\title{
Early-postnatal changes in adiposity and lipids profile by transgenerational developmental programming in swine with obesity/leptin resistance
}

\begin{abstract}
Antonio Gonzalez-Bulnes, Susana Astiz, Cristina Ovilo', Clemente J Lopez-Bote ${ }^{2}$, Raul Sanchez-Sanchez, Maria L Perez-Solana, Laura Torres-Rovira², Miriam Ayuso² and Jorge Gonzalez 3
\end{abstract}

Departamento de Reproducción Animal, INIA, Avenida Puerta de Hierro s/n, Madrid 28040, Spain ${ }^{1}$ Departamento de Mejora Genética Animal, INIA, Ctra. La Coruña km 7·5, Madrid 28040, Spain

${ }^{2}$ Facultad de Veterinaria, Universidad Complutense de Madrid, Madrid 28040, Spain

${ }^{3}$ Micros Veterinaria, Campus de Vegazana, Leon 24007, Spain

\begin{abstract}
Maternal malnutrition during pregnancy, both deficiency and excess, induces changes in the intrauterine environment and the metabolic status of the offspring, playing a key role in the growth, status of fitness/obesity and appearance of metabolic disorders during postnatal life. There is increasing evidence that these effects may not be only limited to the first generation of descendants, the offspring directly exposed to metabolic challenges, but to subsequent generations. This study evaluated, in a swine model of obesity/leptin resistance, the existence and extent of transgenerational developmental programming effects. Pre- and postnatal development, adiposity and metabolic features were assessed in the second generation of piglets, descendant of sows exposed to either undernutrition or overnutrition during pregnancy. The results indicated that these piglets exhibited early-postnatal increases in adiposity and disturbances in lipid profiles compatible with the early prodrome of metabolic syndrome, with liver tissue also displaying evidence of paediatric liver disease. These features indicative of early-life metabolic disorders were more evident in the males that were descended from overfed grandmothers and during the transition from milk to solid feeding. Thus, this study provides evidence supporting transgenerational developmental programming and supports the necessity for the development of strategies for avoiding the current epidemics of childhood overweight and obesity.
\end{abstract}

Correspondence should be addressed to A Gonzalez-Bulnes Email bulnes@inia.es

\section{Introduction}

The incidence of obesity and associated cardiometabolic disorders, traditionally higher in developed countries, is also currently increasing in rapidly developing countries such as India, Brazil, China and Middle East countries (Scully 2012). It is proposed that the main cause is related to major and rapid lifestyle changes http://joe.endocrinology-journals.org DOI: 10.1530/JOE-14-0217
(C) 2014 Society for Endocrinology Printed in Great Britain 
mismatching with genetic background (Kong et al. 2013). In agreement with this theory, people from developing countries are characterised by intrinsic ethnic features, being descended from ancestors adapted to food scarcity and therefore having developed an adaptive thrifty phenotype for surviving in scarce food environment. However, in contrast, they are currently exposed to excess nutrients, mostly in the form of highly caloric obesogenic diets.

The most worrying aspect of the current increase in obesity and comorbidities is that the highest prevalence is found in young and middle-aged populations (Shaw et al. 2010), with individuals of childbearing age therefore being affected. In obese women, the achievement of pregnancy is usually compromised: in the event of pregnancy, changes in the maternal physiological status may induce changes in the intrauterine environment in which the foetus evolves. Currently, the concept of the Developmental Origin of Health and Disease (Gluckman \& Hanson 2004) proposes that changes in the intrauterine environment modify the metabolic status of the foetus, and thereby prenatal programming, play a key role in juvenile growth, in life-time fitness/obesity and in the probability of appearance of metabolic disorders during postnatal life. In consequence, metabolic disorders may be inherited in the first generation of descendants.

The effects of metabolic disorders may persist through multiple generations, due to two different mechanisms. First, by persistence of the exposure to nutritional/metabolic challenges that causes prenatal programming (Dabelea \& Crume 2011, Drake \& Seckl 2011); therefore, by perpetuating the effects of prenatal programming during multiple generations (multigenerational exposure). Second, by transgenerational inheritance of the developmental programming effects (Gallou-Kabani \& Junien 2005, Daxinger \& Whitelaw 2010, Dunn et al. 2011), which occurs by either genomic or epigenetic mechanisms (intergenerational or transgenerational inheritance), without exposure of the descendants to nutritional/metabolic challenges.

The current knowledge of these effects in human medicine is mostly based on results from observational studies, because interventional studies in humans are obviously limited by ethical issues. Thus, there is a necessity for robust and reliable animal models. The most amenable large-animal model for obesity studies is the pig (proportional organ sizes, omnivorous habits, similar lipoprotein metabolism and propensity to sedentary behaviour and obesity; Douglas 1972, Houpt et al. 1979, Spurlock \& Gabler 2008). Specifically, there is a swine breed, the Iberian pig, which is a well-recognised translational model for studies on obesity and associated diseases in humans (Torres-Rovira et al. 2012, 2013).

The Iberian pig faces conditions similar to those than previously cited for humans living in developing countries; i.e. a background of exposure to harsh environments and food scarcity and an adaptive thrifty genotype giving way to obesity in the event of food excess. In fact, the Iberian pigs are homozygous for a leptin receptor gene polymorphism (Ovilo et al. 2010) with effects on food intake, body weight and fat deposition (Ovilo et al. 2005, Muñoz et al. 2009). In consequence, although Iberian pigs are characterised by a high leptin secretion related to the adiposity level (Fernandez-Figares et al. 2007), increases in leptin secretion when obesity occurs are not able to act correctly as an appetite regulator, limiting food intake, in a similar way to human studies (Torres-Rovira et al. 2013). On the other hand, the LEPR polymorphism increases not only insatiability but also lipogenic activity (Morales et al. 2002), contributing to thrifty genotype and obesity in a similar way to the syndrome of leptin resistance described in humans.

The exposure of pregnant Iberian sows to undernutrition or overnutrition induces higher body corpulence and adiposity, development of metabolic syndrome and the prodrome of type- 2 diabetes in the first generation of descendants (Barbero et al. 2013). The objective of this study was to determine the existence and characteristics of transgenerational prenatal programming in the Iberian breed by assessing the phenotype of the second generation of descendants.

\section{Material and methods}

\section{Animals and management}

The study was carried out according to the Spanish Policy for Animal Protection RD1201/05, which meets the European Union Directive 86/609 about the protection of animals used in research. The experiment was specifically assessed and approved (report CEEA 2010/003) by the Instituto Nacional de Investigación y Tecnología Agraria y Alimentaria (INIA) Committee of Ethics in Animal Research, which is the named Institutional Animal Care and Use Committee (IACUC) of the INIA. The animals used in this trial were housed at the INIA Animal Laboratory Unit (Madrid, Spain), which meets the local, national and European requirements for Scientific Procedure Establishments.

Published by Bioscientifica Ltd. 
The experiment involved a total of 92 Iberian piglets. Three experimental groups (CONTROL, OVERFED and UNDERFED) were formed accordingly to the nutritional level to which the grandmothers of these piglets were exposed during the pregnancy from which the mothers of the piglets were born. All the grandmothers had similar body weight, backfat depth and number of parities (two to four) but, nonetheless, were pair-matched among groups; mean body weight and backfat depth were $150.7 \pm 6.4 \mathrm{~kg}$ and $2.5 \pm 0.2 \mathrm{~cm}, 157.5 \pm 6.3 \mathrm{~kg}$ and $2.6 \pm 0.2 \mathrm{~cm}$ and $158.2 \pm 6.5 \mathrm{~kg}$ and $2.5 \pm 0.4 \mathrm{~cm}$ for CONTROL, OVERFED and UNDERFED groups respectively. The CONTROL group ( $n=42$ piglets, 24 males and 18 females) included descendants from grandmothers fed with a standard grain-based diet $(13.0 \%$ crude protein, $2.8 \%$ fat and $3.00 \mathrm{Mcal} / \mathrm{kg}$ of metabolisable energy) for fulfilling their daily maintenance requirements for pregnancy. The second and third groups were the grandchildren of females fed, during the entire pregnancy, with the same diet, but fulfilling either 160\% (OVERFED group, $n=29$ piglets, 11 males and 18 females) or 50\% (UNDERFED group, $n=21,11$ males and ten females) of daily maintenance requirements for gestation, therefore, exposing the preimplantational embryos and the subsequent foetuses of both groups (i.e. the mothers of the studied piglets) to prenatal programming by either nutritional excess or deficiency. All the mothers of the future piglets of this study were maintained under similar conditions during their postnatal development. At 10 months of age, all of them were inseminated with semen from the same Iberian boar after estrus synchronisation with altrenogest (Regumate, MSD, Boxmeer, The Netherlands). The mean body weight and backfat depth at artificial insemination were similar in all the animals, with a mean of $153.7 \pm$ $2.3 \mathrm{~kg}$ and $3.3 \pm 0.3 \mathrm{~cm}, 154.6 \pm 1.7 \mathrm{~kg}$ and $2.3 \pm 0.2 \mathrm{~cm}$ and $150.7 \pm 3.9 \mathrm{~kg}$ and $2.5 \pm 0.4 \mathrm{~cm}$ for CONTROL, OVERFED and UNDERFED groups respectively. After that, all the females were fed, during pregnancy, with the same diet described previously for fulfilling daily maintenance requirements of gestation (i.e. control diet). Thus, at the end of gestation (100 days of pregnancy), mean body weight and backfat depth remained similar in all the mothers $(176.2 \pm 2.9 \mathrm{~kg}$ and $2.9 \pm 0.1 \mathrm{~cm}, 178.0 \pm 2.6 \mathrm{~kg}$ and $2.8 \pm 0.2 \mathrm{~cm}$ and $177.1 \pm 6.6 \mathrm{~kg}$ and $2.7 \pm 0.1 \mathrm{~cm}$ for CONTROL, OVERFED and UNDERFED groups respectively).

The assessment of offspring development was carried out during both the prenatal (from day 50 of pregnancy to delivery) and the early-postnatal period (from birth to weaning at 28 days of age). At weaning, piglets were killed for evaluation of possible differences in organ development, metabolic features, adiposity and fat composition. All the measurements were made without previous knowledge of the treatment groups.

\section{Evaluation of offspring prenatal development}

Evaluation of changes in phenotypic parameters of the developing embryos/foetuses was made at three points over time: 50, 75 and 90 days of pregnancy. Foetal development was determined by measuring trunk diameter and head size (biparietal diameter and occipitonasal length) by ultrasonography. Observations were made with a SonoSite S-Series ultrasound machine equipped with a multifrequency $(2-5 \mathrm{MHz})$ sectorial array probe (SonoSite, Inc., Bothell, WA, USA). For viewing the uterine horns and conceptuses in transverse, frontal or sagittal planes, ultrasound scans were performed by placing the transducer on one abdominal flank and moving it to the opposite flank. After identifying the image of the foetuses, the probe was slowly moved over each conceptus for obtaining the largest sections of its vesicle, head and trunk. Scans were recorded, using the machine's cine-loop option. After that, the size of the structures of interest (trunk diameter and head biparietal diameter and occipito-nasal length) was measured with built-in electronic calipers on the cine-loop recordings. To avoid distortions resulting from the corpulence of an individual embryo/foetus, measurements were taken from all the conceptuses observed at each scanning.

\section{Evaluation of offspring early-postnatal development}

At birth, all the piglets were sexed and each was identified with a number. Immediately, the same measurements performed by ultrasonography (trunk diameter and head size biparietal diameter and occipito-nasal length) were assessed with a hand caliper. At the same time, weight and body length and thoracic and abdominal circumferences (TC and AC) were measured. The number of piglets was made equal in each litter by fostering within the same experimental group and, after that, the piglets remained with mothers in individual pens until weaning. The weight, body length and TC and AC of the piglets were assessed again at the age of 21 days (the usual date for weaning piglets under intensive conditions, when solid feeding is usually introduced) and at 28 days old (when weaning is performed in to traditional management of Iberian sows).

The data obtained for weights at birth and 21 and 28 days of age were used for determining average daily weight

Published by Bioscientifica Ltd. 
gain (ADWG), at two periods (0-21 and 21-28 days), by using the formula:

Final weight $(\mathrm{kg})$ - initial weight $(\mathrm{kg})$

Number of days

Data obtained from body weight and size were used for determining two formulae for calculating BMI at each age-point.

The first formula (BMI1) was extrapolated from human clinical studies:

Weight $(\mathrm{kg}) /$ length $(\mathrm{m})^{2}$.

The second formula (BMI2) takes into account the trunk volume and, thus, incorporates the values of TC and AC, respectively, indicative of the amount of total, visceral and subcutaneous fat in swine (Witczak et al. 2005, Dyson et al. 2006, Christoffersen et al. 2007):

$\frac{\text { Weight }(\mathrm{kg})}{\pi / 3 \times \text { length } \times\left((\mathrm{TC} / 2 \pi)^{2}+(\mathrm{AC} / 2 \pi)^{2}+(\mathrm{TC} / 2 \pi \times \mathrm{AC} / 2 \pi)\right)}$.

\section{Morphometric evaluation and sampling of offspring at weaning}

At day 28, the piglets were sedated with $\mathrm{CO}_{2}$ and, after blood sampling by puncture of the vena cava cranealis with $5 \mathrm{ml}$ sterile heparin vacuum tubes (Vacutainer Systems Europe; Becton Dickinson, Meylan Cedex, France), killed by i.v. injection of T-61 (MSD AH). Blood samples were centrifuged at $1500 \mathrm{~g}$ for $15 \mathrm{~min}$ and the plasma was separated and stored in polypropylene vials at $-20{ }^{\circ} \mathrm{C}$ until assayed for determination of parameters related to metabolism of glucose and lipids.

Immediately, the weight of the head, carcass and main organs (brain, heart, liver, intestine, kidneys and adrenal glands) was assessed; the weight ratios among each organ and body and total viscera were calculated afterwards, at that moment, a section of liver tissue was obtained and kept frozen at $-80^{\circ} \mathrm{C}$ for histological studies. Simultaneously, samples for analysis of subcutaneous adiposity and fat composition were obtained at the level of the head of the last rib, comprising from skin to loin. Fat depth was measured with a ruler and samples were vacuum-packaged in individual bags and stored at $-20^{\circ} \mathrm{C}$ until analysed.

\section{Analysis of metabolic features}

Parameters related to metabolism of lipids (triglycerides, total cholesterol, HDL-C and LDL-C)) were measured with a clinical chemistry analyser (Saturno 300 plus, Crony Instruments s.r.l., Rome, Italy). Parameters related to metabolism of glucose (glucose and insulin) were measured with the same analyser for glucose (Saturno 300 plus) and with a Porcine Insulin ELISA kit (Mercodia $\mathrm{AB}$, Uppsala, Sweden). The assay sensitivity was $0.26 \mathrm{UI} / \mathrm{l}$; the intra-assay variation coefficient was 3.5\%.

\section{Analysis of fat composition}

Intramuscular fat was obtained according to the method developed by Marmer \& Maxwell (1981) from longissimus dorsi muscle samples. Fat extracts were methylated in the presence of sulphuric acid and analysed according to Rey et al. (1997) using a gas chromatograph (Model HP6890; Hewlett Packard Co., Avondale, PA, USA) and a $30 \mathrm{~m} \times$ $0.32 \mathrm{~mm} \times 0.25 \mathrm{~mm}$ cross-linked polyethylene glycol capillary column (Hewlett Packard Innowax). A temperature programme of $170-245^{\circ} \mathrm{C}$ was used. The injector and detector were maintained at $250{ }^{\circ} \mathrm{C}$. The carrier gas (helium) flow rate was $2 \mathrm{ml} / \mathrm{min}$. From individual FA percentages, the saturated FA (SFA), monounsaturated FA (MUFA) and polyunsaturated FA (PUFA) proportions were calculated. SFA is the result of $\mathrm{C} 10: 0+\mathrm{C} 12: 0+\mathrm{C} 14: 0+$ $\mathrm{C} 15: 0+\mathrm{C} 16: 0+\mathrm{C} 17: 0+\mathrm{C} 18: 0+\mathrm{C} 20: 0$. MUFA is the result of $\mathrm{C} 15: 1+\mathrm{C} 16: 1 \mathrm{n}-9+\mathrm{C} 17: 1+\mathrm{C} 18: 1 \mathrm{n}-9+\mathrm{C} 18: 1 \mathrm{n}-7$ $+\mathrm{C} 20: 1$. PUFA is the result of $\mathrm{C} 18: 2 \mathrm{n}-6+\mathrm{C} 18: 3 \mathrm{n}-3+$ C18:4n-3 + C20:3n-9+C20:4n-6. Finally, the desaturation index (DI) is the ratio of MUFA to SFA.

\section{Analysis of liver histology}

The samples of liver tissue were fixed in $4 \%$ paraformaldehyde for $4 \mathrm{~h}$ and processed for conventional histology, being embedded in paraffin and sectioned at $4 \mu \mathrm{m}$. These slides were stained with haematoxylin-eosin, and the characteristics of the tissue were assessed in a blinded fashion by an experienced pathologist (J G). The presence and severity of the histological features of steatohepatitis (steatosis, inflammation and/or ballooning injury) were based on the scoring system developed by Kleiner et al. (2005).

\section{Statistical analyses}

Data were analysed using SPSS 19.0 (IBM, New York, NY, USA). The effects of the diet of the grandmother during pregnancy on body weight, organ development, fat content, and metabolic and histopathological features of the grandchildren were assessed by the ANOVA or by a Kruskall-Wallis test if a Levene's test showed nonhomogeneous variables; a Duncan post-hoc test was performed to contrast the differences among groups. The analysis also included sex of the grandchildren. The effects

Published by Bioscientifica Ltd 
of the maternal diet on the phenotype of embryos, foetuses, newborns and later growing piglets were also tested by within-litter split-plot ANOVA for avoiding the effects of litter size and individual effects from the sows. Statistical analysis of results expressed as percentages was performed after arc-sine transformation of the values for each individual percentage. Results were expressed as the mean \pm s.e.m. and statistical significance was defined as $P<0.05$.

\section{Results}

\section{Patterns of prenatal development}

In all the groups, the size of the conceptuses increased significantly over time of pregnancy $(P<0.0001$; Fig. 1$)$. There were no significant differences among groups in head measurements (biparietal diameter and occipitosnout length) throughout pregnancy. However, the trunk diameter was always significantly larger in foetuses from the OVERFED and UNDERFED groups than in foetuses of the CONTROL group $(P<0.001$ for both), without significant differences between them.

\section{Patterns of early-postnatal development}

At birth, trunk diameter and therefore TC continued to be similar in piglets of the OVERFED and UNDERFED groups and larger in both groups than in newborn piglets of the CONTROL group $(P<0.05)$. In the same way, trunk length was also similar in newborn piglets of the OVERFED and
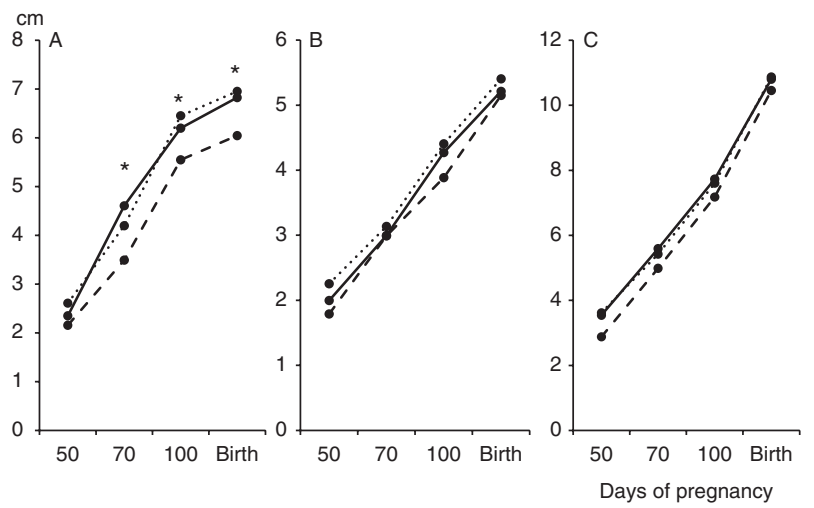

Figure 1

Effects of transgenerational developmental programming on prenatal growth. Changes over time of pregnancy in the mean values of trunk diameter (A), biparietal diameter (B) and occipito-nasal length (C) of the second generation of offspring from control sows (dashed line) and sows exposed to over- and underfeeding during gestation (continuous and dotted lines respectively). Indications of S.E.M. have been omitted for clarity of the figure. Asterisks denote significant differences $(* P<0.001)$.
UNDERFED groups and larger in these groups than in piglets of the CONTROL group $(P<0.0005)$. Thus, as a result, trunk volume was larger in piglets of the OVERFED and UNDERFED groups than in piglets of the CONTROL group $(P<0.05$; Fig. 2). However, there were no significant differences among the three groups in the birth weight and, moreover, in the relationships between body weight and size (expressed as BMI1 and BMI2). There were no significant influence of sex within the different groups of treatment.

The assessment of the ADWG (Table 1) showed that CONTROL group piglets grew faster than OVERFED and UNDERFED group animals $(P<0.005$ and $P<0.0001$ respectively) from day 1 to day 21 . These differences in ADWG were reflected in differences in weight, BMI1 and BMI2 at 21 days of age, when these parameters were higher for animals of the CONTROL group than in animals of the OVERFED and UNDERFED groups $(P<0.05$ for weight and $P<0.001$ for BMIs; Fig. 2). On the other hand, the differences between OVERFED and UNDERFED groups were not statistically significant.

From day 21 to day 28, daily growth was similar in piglets of the OVERFED and UNDERFED groups and faster in both groups than in the CONTROL group $(P<0.001$ for both). Therefore, at 28 days of age, the piglets of the CONTROL and OVERFED groups were similar in weight. However, both groups still remained heavier than animals of the UNDERFED groups $(P<0.05)$. The values for BMI1 were similar among the three groups; however, trunk volume was smaller for piglets in the OVERFED and UNDERFED groups than in piglets of the CONTROL group $(P<0.05$ for both); thus, values for BMI2 were similar for the animals of the OVERFED and UNDERFED groups and significantly higher in both groups than in piglets of the CONTROL group $(P<0.001)$.

The effects of sex were mainly detected within treatments. Males of the CONTROL group had higher postnatal ADWG and, thus, they were significantly heavier and larger than their female littermates at 21 and 28 days of age $(P<0.05)$. Conversely, there were no differences in these values between males and females of the UNDERFED group, neither at 21 nor 28 days of age. Thus, the males of the UNDERFED group were smaller $(P<0.01)$ and lighter $(P<0.05)$ than their male counterparts of the CONTROL and OVERFED groups, but their female littermates were similar to females of the CONTROL and OVERFED groups. Finally, in the OVERFED group, there was no significant effect of the sex at day 21, but males had a higher ADWG between 21 and 28 days $(P<0.01)$ and, thus, a higher weight at day $28(P<0.05)$.

Published by Bioscientifica Ltd 

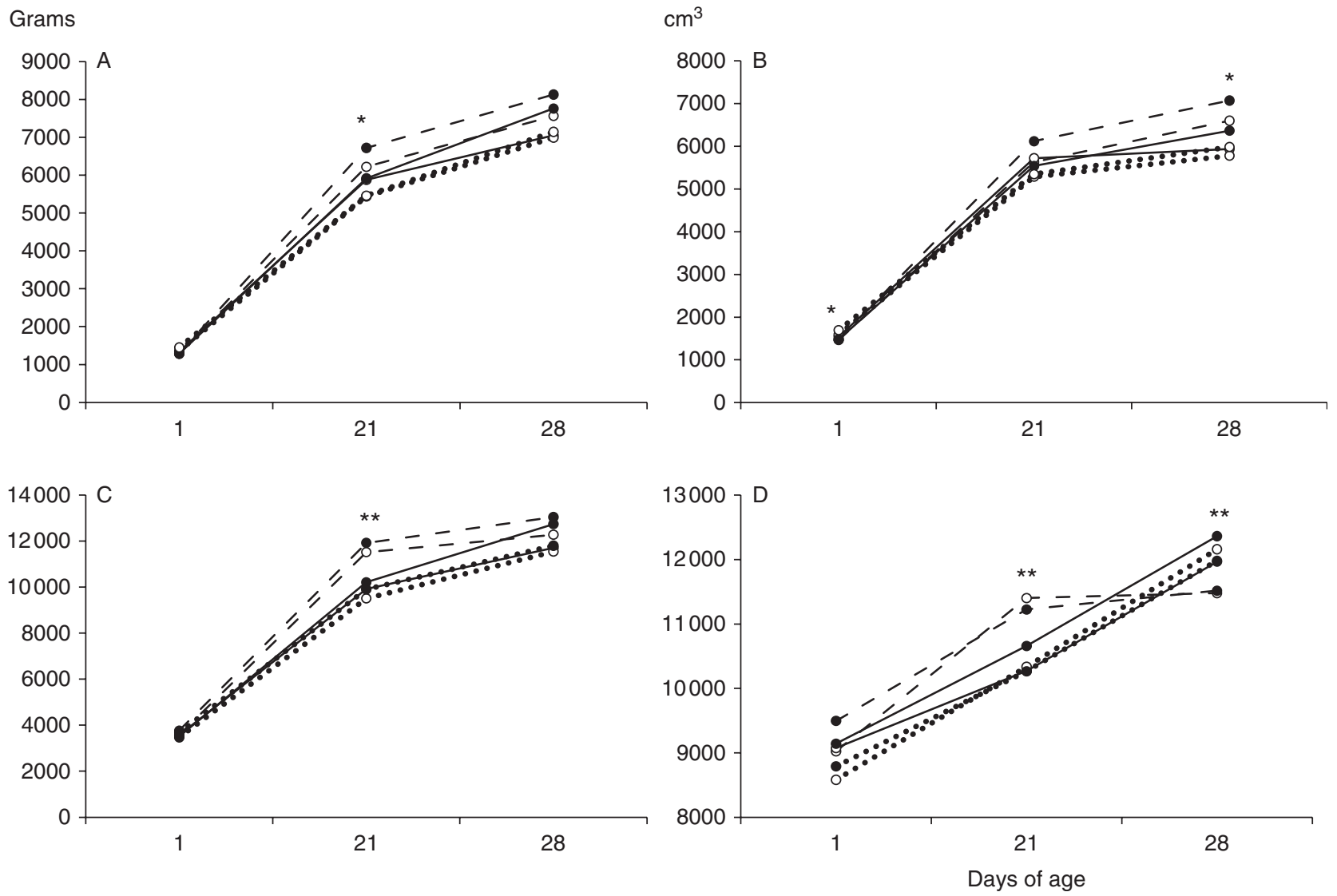

Figure 2

Effects of transgenerational developmental programming on postnatal growth. Changes over time (piglets age) in the mean values of body weight and volume ( $A$ and $B$ respectively) and BMIs (BMI1 in C and BMI2 in D) of the second generation of male (black dots) and female (white dots)

offspring from control sows (dashed line) and sows exposed to over- and underfeeding during gestation (continuous and dotted lines respectively). Indications of S.E.M. have been omitted for clarity of the figure. Asterisks denote significant differences $(* P<0.05$ and $* * P<0.001)$.

\section{Morphological features at weaning}

At weaning (28 days of age), the weight and size of the carcass and head in piglets of the OVERFED and CONTROL groups were similar, in agreement with the entire-body results; carcasses and heads of males were

heavier than those of female littermates in both groups (Table 2). The males of the UNDERFED group had lower weights of the carcass $(P<0.05)$, but not of the head, and smaller trunk volumes $(P<0.01)$ than males of the CONTROL group. These differences were not significant

Table 1 Changes in average daily weight gain (g/day \pm s.E.m.) during lactation in the second generation of male and female offspring of control sows and sows exposed to overfeeding and underfeeding during gestation

\begin{tabular}{|c|c|c|c|c|c|c|}
\hline \multirow[b]{2}{*}{ Days of age } & \multicolumn{2}{|c|}{ CONTROL, mean } & \multicolumn{2}{|c|}{ OVERFED, mean } & \multicolumn{2}{|c|}{ UNDERFED, mean } \\
\hline & Female & Male & Female & Male & Female & Male \\
\hline \multirow[t]{2}{*}{$1-28$} & \multicolumn{2}{|c|}{$221.0 \pm 5.8$} & \multicolumn{2}{|c|}{$235.6 \pm 7.5$} & \multicolumn{2}{|c|}{$208.4 \pm 7.7$} \\
\hline & \multicolumn{2}{|c|}{$251.1 \pm 7.1^{\mathrm{e}, \mathrm{k}}$} & \multicolumn{2}{|c|}{$\begin{array}{c}214.8 \pm 5.8^{a} \quad 237.2 \pm 10.9^{b} \\
215.2 \pm 8.9^{f}\end{array}$} & \multicolumn{2}{|c|}{$192.2 \pm 8.7^{1}$} \\
\hline \multirow[t]{2}{*}{$21-28$} & \multicolumn{2}{|c|}{$175.4 \pm 14.6^{\mathrm{g}}$} & \multicolumn{2}{|c|}{$\begin{array}{r}230.1 \pm 15.2^{\mathrm{h}} \\
230.1 \pm 1.3\end{array}$} & \multicolumn{2}{|c|}{$229.4 \pm 13.9^{h}$} \\
\hline & $170.7 \pm 12.9^{a}$ & $180.1 \pm 26.6^{a}$ & $210.7 \pm 20.5^{c}$ & $263.3 \pm 16.2^{d}$ & $221.4 \pm 20.6$ & $240.8 \pm 17.8$ \\
\hline
\end{tabular}


Table 2 Mean weights ( $\mathrm{g} \pm$ S.E.M.) of different structures and viscerae of the second generation of male and female offspring of control sows and sows exposed to overfeeding and underfeeding during gestation

\begin{tabular}{|c|c|c|c|}
\hline & \multicolumn{2}{|c|}{ CONTROL, mean } & \\
\hline & la & Male & \\
\hline Entire body & \multicolumn{2}{|c|}{$7863.4 \pm 205.9^{a}$} & 7046.2 \\
\hline Head & $808.7 \pm 19.3^{836.2}$ & $\begin{array}{l} \pm 18.7 \\
865.8 \pm 31.6^{b}\end{array}$ & 821.7 \\
\hline \multirow{2}{*}{$\begin{array}{l}\text { Carcass } \\
\text { Total viscerae }\end{array}$} & $\begin{array}{r}5765.9 \\
5489.0 \pm 201.0^{\mathrm{a}} \\
1157\end{array}$ & $\begin{array}{l}+181.1^{a} \\
6062.5 \pm 294.0^{b}\end{array}$ & 5123.1 \\
\hline & $1124.4 \pm 23.6^{\mathrm{a}}$ & $1192.1 \pm 40.6$ & \\
\hline Liver & & $245.5+5.8^{c, i}$ & \\
\hline \multirow[t]{3}{*}{ Intestine } & \multicolumn{2}{|c|}{$506.5 \pm 10.1$} & \\
\hline & $\begin{array}{r}497.7 \pm 11.3 \\
50.0\end{array}$ & & 448.7 \\
\hline & $48.2 \pm 1.3^{c, e}$ & & 41. \\
\hline \multicolumn{4}{|c|}{ s denote statistically significant differences $\left({ }^{a \neq b} P<0.05\right.$; } \\
\hline \multirow{2}{*}{\multicolumn{4}{|c|}{$\begin{array}{l}\text { when compared with the females, because females of the } \\
\text { UNDERFED group had similar carcass weight and size to } \\
\text { that of CONTROL group females and even to their male } \\
\text { littermates of the UNDERFED group. }\end{array}$}} \\
\hline & & & \\
\hline \multicolumn{4}{|c|}{$\begin{array}{l}\text { The absolute weights of some large viscerae were } \\
\text { overall lower in the UNDERFED and OVERFED groups } \\
\text { than in the CONTROL group. It is important to highlight } \\
\text { that the absolute weight of the liver was higher in piglets } \\
\text { of the CONTROL group when compared with animals } \\
\text { of the OVERFED and UNDERFED groups ( } P<0.0005 \text { and } \\
P<0.01 \text { respectively), independently from sex. Conver- } \\
\text { sely, the relative weight of liver/viscerae was higher in } \\
\text { both the OVERFED and UNDERFED groups than in the } \\
\text { CONTROL group }(P<0.05 \text { and } P<0.0001 \text { respectively). }\end{array}$} \\
\hline
\end{tabular}

OVERFED, mean

Female Male

$7295.0 \pm 267.2^{a}$

$046.2 \pm 350.2^{\mathrm{a}} \quad 7757.1 \pm 368.3^{\mathrm{b}}$

$840.7 \pm 20.3$

$81.7 \pm 23.4^{\mathrm{a}} \quad 875.9 \pm 36.8^{\mathrm{b}}$

$5218.0 \pm 232.1^{\mathrm{a}}$

$23.1 \pm 306.2^{\mathrm{a}} \quad 5394.3 \pm 362.1^{\mathrm{b}}$

$1027.5 \pm 31.6$

$86.5 \pm 33.6^{\mathrm{b}} \quad 1103.6 \pm 57.9$

$206.2 \pm 9.7^{j}$

$94.4 \pm 10.7^{f} \quad 228.0 \pm 17.6^{f}$ $460.4 \pm 14.7^{\mathrm{a}}$

$48.7 \pm 19.6^{a} \quad 482.0 \pm 20.3^{a}$ $44.3+1.8^{\mathrm{b}}$

$41.2 \pm 1.3^{\mathrm{d}} \quad 50.1 \pm 3.8^{\mathrm{b}}$

\begin{tabular}{|c|c|}
\hline \multicolumn{2}{|c|}{ UNDERFED, mean } \\
\hline Female & Male \\
\hline \multicolumn{2}{|c|}{$7052.9 \pm 210.8^{b}$} \\
\hline $6990.0 \pm 275.1$ & 7142.9 \\
\hline \multicolumn{2}{|c|}{$819.2 \pm 22.4$} \\
\hline $\begin{array}{r}814.4 \pm 27.4 \\
5002 .\end{array}$ & $\begin{array}{r}826.0 \\
187.2^{\mathrm{b}}\end{array}$ \\
\hline $\begin{array}{r}5050.0 \pm 244.6 \\
1121\end{array}$ & $\begin{aligned} & 4935.7 \pm 312.2^{2} \\
+ & 40.0\end{aligned}$ \\
\hline $\begin{array}{r}1087.0 \pm 43.2 \\
211 .\end{array}$ & $\begin{aligned} & 1169.6 \pm 75.6 \\
- & 8.1^{d}\end{aligned}$ \\
\hline $\begin{array}{r}203.6 \pm 10.5^{f} \\
515 .\end{array}$ & $\begin{array}{l}223.9 \pm 12.2 \\
23.7^{b}\end{array}$ \\
\hline $499.3 \pm 23.5^{\mathrm{b}}$ & $\begin{array}{l}537.9 \pm 48.0^{\mathrm{b}} \\
1.6^{\mathrm{b}}\end{array}$ \\
\hline $43.3 \pm 2.3^{f}$ & $45.7 \pm 2.4^{b}$ \\
\hline
\end{tabular}

Table 3 Mean values (mg/dl \pm s.E.m.) of parameters of carbohydrate and lipid metabolism of the second generation of male and female offspring of control sows and sows exposed to overfeeding and underfeeding during gestation

\begin{tabular}{|c|c|c|}
\hline & \multicolumn{2}{|c|}{ CONTROL, mean } \\
\hline & Female & Male \\
\hline \multirow[t]{2}{*}{ Glucose } & \multicolumn{2}{|c|}{$136.4 \pm 7.7$} \\
\hline & $142.2 \pm 12.9$ & $130.2 \pm 8.1$ \\
\hline \multirow[t]{2}{*}{ Fructosamine } & \multicolumn{2}{|c|}{$191.0 \pm 7.7^{9}$} \\
\hline & $193.1 \pm 11.8^{a}$ & $188.9 \pm 10.3$ \\
\hline \multirow[t]{2}{*}{ Triglycerides } & \multicolumn{2}{|c|}{$89.5 \pm 11.0$} \\
\hline & $99.1 \pm 19.3$ & $79.2 \pm 9.5^{\mathrm{a}}$ \\
\hline \multirow[t]{2}{*}{ Total cholesterol } & \multicolumn{2}{|c|}{$212.7 \pm 11.9$} \\
\hline & $244.0 \pm 15.4$ & $179.2 \pm 14.0^{a}$ \\
\hline \multirow[t]{2}{*}{ HDL-C } & \multicolumn{2}{|c|}{$54.1 \pm 4.5$} \\
\hline & $60.9 \pm 4.6$ & $46.9 \pm 7.5^{\mathrm{a}}$ \\
\hline \multirow[t]{2}{*}{ LDL-C } & \multicolumn{2}{|c|}{$140.7 \pm 8.4$} \\
\hline & $163.3 \pm 12.1$ & $116.5 \pm 7.0^{\mathrm{a}}$ \\
\hline
\end{tabular}

\begin{tabular}{|c|c|}
\hline \multicolumn{2}{|c|}{ OVERFED, mean } \\
\hline Female & Male \\
\hline \multicolumn{2}{|c|}{$146.0 \pm 4.5$} \\
\hline $145.2 \pm 5.2$ & $147.6 \pm 9.1$ \\
\hline \multicolumn{2}{|c|}{$228.0 \pm 4.6^{\mathrm{a}, \mathrm{h}}$} \\
\hline $232.1 \pm 5.4^{b}$ & $220.4 \pm 8.5$ \\
\hline \multicolumn{2}{|c|}{$108.7 \pm 10.2$} \\
\hline $103.2 \pm 12.5$ & $119.0 \pm 18.1^{b}$ \\
\hline \multicolumn{2}{|c|}{$278.9 \pm 24.9$} \\
\hline $305.7 \pm 35.3^{a}$ & $228.9 \pm 18.5^{b}$ \\
\hline \multicolumn{2}{|c|}{$68.4 \pm 6.0$} \\
\hline $67.2 \pm 6.4$ & $70.5 \pm 13.1^{b}$ \\
\hline \multicolumn{2}{|c|}{$188.8 \pm 21.9$} \\
\hline $217.9 \pm 29.6^{a}$ & $134.6 \pm 17.9^{b}$ \\
\hline
\end{tabular}

\begin{tabular}{|c|c|}
\hline \multicolumn{2}{|c|}{ UNDERFED, mean } \\
\hline Female & Male \\
\hline \multicolumn{2}{|c|}{$158.8 \pm 8.1$} \\
\hline \multicolumn{2}{|c|}{$212.2 \pm 7.7^{\mathrm{b}}$} \\
\hline \multicolumn{2}{|c|}{$120.5 \pm 18.3^{b}$} \\
\hline $\begin{array}{r}130.9 \pm 25.5 \\
19\end{array}$ & $\begin{array}{l}105.6 \pm 26.6 \\
17.4\end{array}$ \\
\hline $221.7 \pm 21.6$ & $\begin{array}{l}145.4 \pm 20.0^{a} \\
5.8\end{array}$ \\
\hline $51.2 \pm 8.1$ & $44.9 \pm 8.4^{a}$ \\
\hline $144.3 \pm 21.3$ & $79.4 \pm 15.9^{a}$ \\
\hline
\end{tabular}

Different superscripts denote statistically significant differences $\left({ }^{\mathrm{a} \neq \mathrm{b}} P<0.05 ;{ }^{\mathrm{c} \neq \mathrm{d}} P<0.01 ;{ }^{\mathrm{e} \neq \mathrm{f}} P<0.005 ;{ }^{\mathrm{g} \neq \mathrm{h}} P<0.001 ;{ }^{\mathrm{i} \neq \mathrm{j}} P<0.0005 ;{ }^{\mathrm{k} \neq \mathrm{l}} P<0.0001\right)$.

http://joe.endocrinology-journals.org DOI: $10.1530 / \mathrm{JOE}-14-0217$
(๑) 2014 Society for Endocrinology Printed in Great Britain
The OVERFED group also exhibited lower relative intestine/total viscerae and total viscerae/entire body weights than the UNDERFED group due to a lower absolute weight of the intestine $(P<0.05$ for all the values); these weights and ratios were also numerically lower than those for the CONTROL group. Finally, animals of the OVERFED group also had lower relative adrenal glands/total viscerae weights than those of the UNDERFED and CONTROL groups $(P<0.05$ and $P<0.005$ respectively).

\section{Metabolic features at weaning}

The assessment of plasma indicies of glucose and lipid metabolism also showed significant differences 
among groups (Table 3). Overall, there were no significant differences in plasma glucose concentrations, but plasma fructosamine levels were higher in the OVERFED than in the CONTROL and UNDERFED groups $(P<0.001$ and $P<0.05$ respectively), with differences being mainly driven by higher values in females $(P<0.05)$. On the other hand, concentrations of plasma lipids were affected by group and sex; females of the three groups had numerically higher values for all the parameters (excepting triglycerides and HDL-C in the OVERFED group), but significant differences were only found for total and LDL-C in the OVERFED group $(P<0.05)$. The comparison among the female piglets from the three groups showed no significant differences, but males of the OVERFED group showed significantly higher plasma triglycerides concentrations than CONTROL group males $(P<0.05)$ and significantly higher levels of total, HDL-C and LDL-C than males of both the UNDERFED and CONTROL groups $(P<0.05)$.

\section{Adiposity and fat composition at weaning}

The amount of subcutaneous backfat depth and the content of intramuscular fat were similar in piglets of the OVERFED and UNDERFED groups and higher in both groups than in CONTROL group piglets $(P<0.05$ for subcutaneous fat and $P<0.001$ for intramuscular fat;
Table 4). There were no significant influences of sex either in subcutaneous or intramuscular adiposity.

There were also differences in fat composition among groups (Table 4). In brief, CONTROL group piglets had a higher proportion of SFA and a lower FA desaturation index (FADI) than OVERFED and UNDERFED group piglets $(P<0.05)$, with no detectable effects of sex.

\section{Tissue-characteristics of liver}

Microscopic evaluation of the liver samples detected evidence of early steatohepatitis similar to type II nonalcoholic steatohepatitis (NASH) in some of the piglets (Fig. 3). Specifically, there was evidence of steatosis ( $>5 \%$ of the hepatocytes) in $76.1 \%$ of the UNDERFED, $41.3 \%$ of the OVERFED $(P<0.05$ with UNDERFED) and $16.7 \%$ of the CONTROL group piglets $(P<0.001$ with UNDERFED and $P<0.01$ with OVERFED). The presence of steatosis reaching score 2 ( $>33-66 \%$ of the hepatocytes) was similar in the UNDERFED and OVERFED groups (33.3 and 20.6\% respectively; $P<0.005$ with CONTROL for both groups). A steatosis score of 3 (severe, $>66 \%$ of the hepatocytes) was found in one piglet of the UNDERFED group. On the other hand, the presence of mild inflammation was higher in animals of the OVERFED than the UNDERFED group (58.6 vs $33.3 \%$ respectively; $P<0.05$ between them and $P<0.005$ with CONTROL). Finally, there was absence of ballooning injury in all the samples.

Table 4 Mean values ( \pm s.E.m.) of subcutaneous backfat depth $(\mathrm{cm})$; percentage of intramuscular fat content and percentages of saturated, monounsaturated and polyunsaturated fatty acids (SFA, MUFA and PUFA respectively) and fatty acids desaturation index (FADI) in the second generation of male and female offspring of control sows and sows exposed to overfeeding and underfeeding during gestation

\begin{tabular}{|c|c|c|c|c|c|c|}
\hline & \multicolumn{2}{|c|}{ CONTROL, mean } & \multicolumn{2}{|c|}{ OVERFED, mean } & \multicolumn{2}{|c|}{ UNDERFED, mean } \\
\hline & Female & Male & Female & Male & Female & Male \\
\hline \multirow{2}{*}{$\begin{array}{l}\text { Subcutaneous } \\
\text { backfat depth }\end{array}$} & \multicolumn{2}{|c|}{$0.6 \pm 0.1^{a}$} & \multicolumn{2}{|c|}{$1.6 \pm 0.1^{b}$} & \multicolumn{2}{|c|}{$1.4 \pm 0.1^{b}$} \\
\hline & $0.6 \pm 0.1^{a}$ & $0.6 \pm 0.1^{\mathrm{a}}$ & $1.6 \pm 0.1^{b}$ & $1.7 \pm 0.1^{\mathrm{b}}$ & $1.5 \pm 0.1^{b}$ & $1.4 \pm 0.1^{b}$ \\
\hline \multirow{2}{*}{$\begin{array}{l}\text { Percentage of } \\
\text { intramuscular fat }\end{array}$} & \multicolumn{2}{|c|}{$3.3 \pm 0.6^{\mathrm{g}}$} & \multicolumn{2}{|c|}{$10.1 \pm 0.9^{h}$} & \multicolumn{2}{|c|}{$11.1 \pm 1.9^{h}$} \\
\hline & $3.6 \pm 0.6^{\mathrm{e}}$ & $2.9 \pm 0.5^{\mathrm{e}}$ & $10.2 \pm 0.9^{f}$ & $9.7 \pm 0.8^{f}$ & $11.3 \pm 2.1^{f}$ & $10.9 \pm 1.7^{f}$ \\
\hline SFA & \multicolumn{2}{|c|}{$36.3 \pm 0.2^{\mathrm{a}}$} & \multicolumn{2}{|c|}{$35.5 \pm 0.2^{\mathrm{b}}$} & \multicolumn{2}{|c|}{$35.5 \pm 0.3^{\mathrm{b}}$} \\
\hline MUFA & \multicolumn{2}{|c|}{$43.8 \pm 0.4$} & \multicolumn{2}{|c|}{$42.9 \pm 0.8$} & $35.4 \pm 0.4^{b}$ & $\begin{array}{l}35.6 \pm 0.4 \\
8\end{array}$ \\
\hline & $44.3 \pm 0.5$ & $43.2 \pm 0.6$ & $43.2 \pm 1.1$ & $42.3 \pm 1.0$ & $45.1 \pm 1.1$ & $43.2 \pm 1.2$ \\
\hline PUFA & \multicolumn{2}{|c|}{$19.9 \pm 0.3$} & \multicolumn{2}{|c|}{$21.6 \pm 0.7$} & \multicolumn{2}{|c|}{$20.2 \pm 0.7$} \\
\hline \multirow[t]{2}{*}{ FADI } & \multicolumn{2}{|c|}{$1.20 \pm 0.01^{\mathrm{a}}$} & \multicolumn{2}{|c|}{$1.22 \pm 0.03^{\mathrm{b}}$} & \multicolumn{2}{|c|}{$1.24 \pm 0.03^{b}$} \\
\hline & $1.23 \pm 0.02^{\mathrm{a}}$ & $1.18 \pm 0.01^{a}$ & $1.25 \pm 0.04^{b}$ & $1.21 \pm 0.02^{\mathrm{a}}$ & $1.28 \pm 0.04^{b}$ & $1.21 \pm 0.02^{a}$ \\
\hline ifforont sounorcrrints de & ical the lat & differenc & 05. $c \neq d p$ & $00005 . g \neq h$ & ј $P<000$ & 001). \\
\hline $\begin{array}{l}\text { http://joe.endocrinology-jo } \\
\text { DOI: } 10.1530 / J O E-14-0217\end{array}$ & org & $\begin{array}{l}14 \text { Society for Enc } \\
\text { Printed in G }\end{array}$ & $\begin{array}{l}\text { logy } \\
\text { tain }\end{array}$ & scientifica Ltd. & & \\
\hline
\end{tabular}



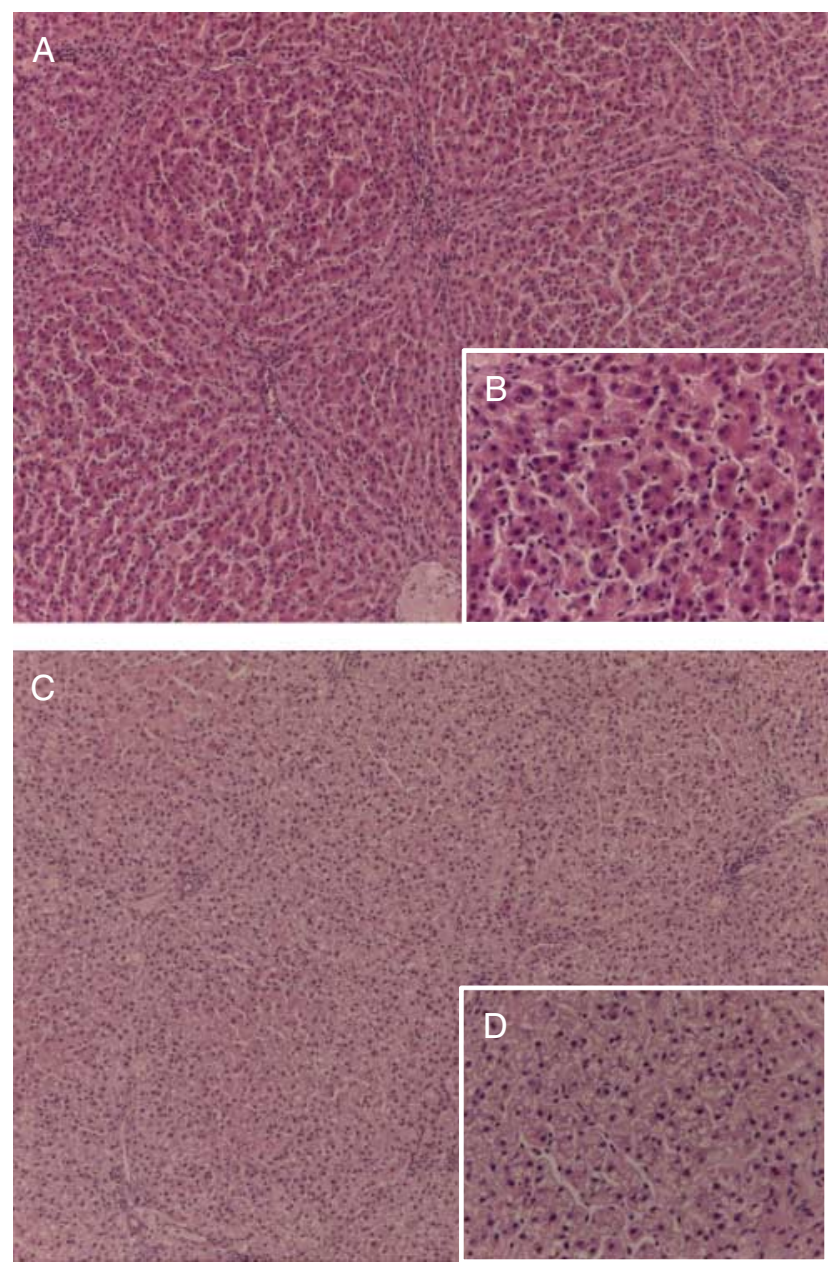

Figure 3

Effects of transgenerational developmental programming on tissuecharacteristics of livers. Histological images of the liver $(10 \times$ and $40 \times$ in the insets) in a piglet of the CONTROL group ( $A$ and $B$ ) with normal hepatocytes without cytoplasmic changes (periportal fibrosis is a normal feature in the histological architecture of the swine liver) and a piglet of the UNDERFED group ( $C$ and $D$ ) with microvesicular steatosis in almost all the hepatocytes. A full colour version of this figure available via http://dx.doi.org/ 10.1530/JOE-14-0217.

\section{Discussion}

The results of this study indicate the existence of transgenerational developmental programming in a swine model of thrifty genotype, leptin resistance and obesity which modifies growth patterns, adiposity and lipid profiles of the second generation of descendants at such early stages as during suckling. These changes are the results of an interaction between sex of the individual and type of nutritional challenge of its ancestors (deficiency or excess).

In brief, the results of our previous studies (Gonzalez-Bulnes et al. 2012, Barbero et al. 2013,
Ovilo et al. 2014) indicated that the first generation of female descendants from sows exposed to nutritional programming, both by deficiency and excess, displayed accelerated early-postnatal growth from the very first days of life, reaching weights similar to their male littermates during the lactation period. The transition from lactation to solid diet was characterised by a higher weight gain in both male and female progeny of sows exposed to either excess or deficiency these finally having higher weight and adiposity than their control counterparts, as well as altered fatty acid metabolism. This effect was more evident in male offspring of sows exposed to overnutrition, which also indicated increased concentrations of plasma lipids.

The results of the current study indicated that the second generation of descendants of females exposed to nutritional challenges during pregnancy (both deficiency and excess; designated previously as UNDERFED and OVERFED groups, respectively) exhibited a higher body size than the animals of the CONTROL group during prenatal development and at birth. However, this pattern was not related to a higher birth weight or a higher growth rate in the first days of life, which resembles the results from previous studies carried out on the first generation of Iberian pigs exposed to prenatal programming (Barbero et al. 2013). Our findings are in agreement with those of previous studies which indicate that, in pigs, growth and maturation of foetuses are markedly determined during the last few days of gestation (McPherson et al. 2004, Foxcroft et al. 2006, Lin et al. 2012), even more in antique breeds such as Iberian swine (Charneca et al. 2010). This ability to modulate terminal foetal growth may explain the lack of differences among newborns programmed either by nutritional excesses or deficiencies and nonchallenged (Ravelli et al. 1976, Roseboom et al. 2001).

Conversely, males and females of the CONTROL group grew faster than their counterparts in the UNDERFED and OVERFED groups during the first 21 days of lactation, which is the usual date for weaning piglets under intensive conditions. Possible critical points for these differences in favour of the CONTROL group may be a lower quantity or quality of milk in the sows that were exposed to nutritional challenges during their foetal development (because such characteristics are highly influenced by nutritional and metabolic cues in all mammals; Shingfield et al. 2013), a lower capacity of the neonates for endogenous glucose production (which is critical for adequate early-postnatal development; Hammon et al. 2012) and/or a lower ability of the offspring to absorb and utilize milk nutrients (in a way similar to first generations of nutritionally programmed piglets; D'Inca et al. 2011). It is not possible to

Published by Bioscientifica Ltd. 
check these hypotheses under the conditions of this study, but our results pave the way for future studies focused on both animal production and biomedicine.

In this study, the piglets were weaned at 28 days of age, accordingly to the traditional management of the Iberian breed. The objective of this practice is to allow the suckling of the piglets during the initiation of solid diet and, therefore, to increase their performance during this transition period. In fact, the combination of milk and solid food favours temporary overfeeding of the piglets. In the current experiment, this situation induced higher weight gains in piglets of the UNDERFED and OVERFED groups of both sexes when compared with their CONTROL group counterparts. However, these higher weight gains were not accompanied by equivalent increases in body size; piglets of the UNDERFED and OVERFED groups were smaller and therefore had higher BMI2 than CONTROL group piglets at weaning. At that moment, there was also a higher content of intramuscular fat in both groups than in CONTROL group animals. Altogether, these data provided evidence of a trend towards early-postnatal obesity in the progeny of nutritionally challenged sows.

The composition of the intramuscular fat in animals of both groups was different when compared with animals in the control group, indicating an altered fatty acid metabolism. The essential finding was that piglets in the UNDERFED and OVERFED groups exhibited a higher fatty acid DI, a potential biomarker of metabolic risk (Warensjö et al. 2006, Yee et al. 2012), than CONTROL group piglets. The DI indicates the activity of fatty acids desaturases (mainly of the stearoyl-CoA desaturase enzyme 1; SCD1). Thus, increased SCD1 activity is indicative of enhanced lipogenesis and a trend towards obesity and metabolic disorders (Attie et al. 2002, Hulver et al. 2005, Poudyal \& Brown 2011). Specifically, a low content of stearic acid and/or a high content of palmitoleic acid (the precursor and product of SCD1 activity respectively), as in our study, are considered markers of abdominal adiposity, triglyceridaemia and insulin dysregulation (Paillard et al. 2008, Caron-Jobin et al. 2012).

Concomitantly, the relative weight of the liver was higher in the descendants of prenatally programmed sows. The development of the liver is critical for enhancing hepatic glucogenic capacity during the nutritional transition from a continuous maternal supply of nutrients via the placenta to a more intermittent supply from the milk via the intestine after birth (Shelley 1961, Dawkins 1966, Trahair \& Sangild 1997) and, therefore, adequate liver development favours postnatal growth (Antipatis et al. 2000). It has been described that foetuses undergoing adverse nutritional conditions have a faster liver development through a 'liver-sparing effect' (Haugen et al. 2005). Therefore, our finding may be a transgenerational effect, supported by the concomitant findings of lower weights of intestine and adrenal glands. However, under the conditions reported in this study, we cannot state whether the liver enlargement was established during prenatal development, or at postnatal stages, in addition to the aforementioned changes in fat distribution and fatty acid metabolism. In this last case, the increase in the relative liver weight may be the earlier symptom of a liver disorder; paediatric non-alcoholic fatty liver disease (NAFLD; Fishbein et al. 2005, 2006). Paediatric NAFLD is increasingly being detected in obese children and linked with metabolic syndrome and insulin resistance (Sundaram et al. 2009); especially, in developing countries such as Brazil, China, Middle Eastern countries and India (Suano de Souza et al. 2008, Meng et al. 2011, El-Koofy et al. 2012, Bramlage et al. 2013). In any case, our current results are paving the way for further studies whereby swine, and specifically Iberian swine, serve as an amenable model.

Thus, results of this study indicate that the exposure of Iberian pigs to undernutrition or overnutrition during pregnancy induces transgenerational effects that make the subsequent generations more prone to adiposity and metabolic disorders. Moreover, our previous and current results (Barbero et al. 2013) indicate that, in both the first and second generation, these alterations may be stronger in the case of exposure to an excess of nutrients and, specially, in male offspring.

The piglets of the OVERFED group in the present trial, both males and females, had a higher amount of subcutaneous fat and a higher plasma fructosamine levels compared with their counterparts in both the CONTROL and UNDERFED groups. Plasma concentration of fructosamine indicates the amount of glycated protein and is considered a good index of glucose levels over a preceding period of 2-3 weeks; in our particular case of suckling piglets, this parameter may be even more reliable that a single-point glucose determination. Thus, these results would indicate a certain impairment of glucose regulation, possibly related to increases in fat-content because adiposity increases insulin resistance in human young individuals (Elder et al. 2006, Scheen 2010).

The features evidencing early-life metabolic disorders were more evident, as aforementioned, in males of the OVERFED group. These piglets grew faster than their female littermates and the other males during the period of transition to solid feeding (21-28 days), but the critical finding is that they exhibited a higher plasma

Published by Bioscientifica Ltd 
concentration of triglycerides and cholesterol than the males of the other groups. Plasma lipid content at earlylife stages is related to genetics, food intake patterns and adiposity (Vobecky et al. 1979, Ward et al. 1980). An increase in triglyceridaemia is the primary lipid abnormality of obesity in childhood, being considered a precocious biomarker of impaired glucose tolerance, metabolic syndrome and later diabetes (Koyama et al. 1997, Slyper 1998, Kwiterovich 2008). The second lipid abnormality is hypercholesterolaemia, which evolves to dyslipidaemia (enlarged triglyceridaemia and cholesterolaemia with low HDL-C ratio) at more advanced stages of metabolic syndrome and diabetes (TemelkovaKurktschiev \& Hanefeld 2004, Nesto 2005); however, we conjecture that the piglets used in the current study are too young to develop such symptoms.

The data providing evidence of higher plasma contents of triglycerides and cholesterol in the current study are also remarkable because hypertriglyceridaemia is usually found in paediatric NAFLD; in some cases, concomitantly with hypercholesterolaemia (Roberts 2005, El-Kabbany et al. 2013). Therefore, these results support the previous evidence of the initial stages of NAFLD in the progeny of nutritionally challenged Iberian sows. The results of the histopathological evaluation of the liver tissue were definitive for establishing the presence of NAFLD in some of the piglets. Evidence was found of early steatohepatitis similar to type II NASH, which is the most usual in paediatric NAFLD (Schwimmer et al. 2005). Occurrence of NAFLD after prenatal programming has been previously found in male mice and not in female mice, but in the first generation and during adulthood (Pruis et al. 2014), which supports the susceptibility of the Iberian pigs to changes in nutritional and metabolic status.

In conclusion, this study has yielded evidence supporting transgenerational developmental programming in a swine model of thrifty genotype and leptin resistance. These phenotypic changes may be the result of the interaction between genotypic characteristics of leptin resistance and developmental programming, because mutation of the leptin receptor may influence the response to the maternal environment. The consequences, determined by the sex of the individual and the type of nutritional challenge of its ancestors (deficiency or excess), were evident at such early stages as during lactation and transition to solid diets, with higher adiposity and disturbances compatible with the early prodrome of metabolic syndrome and paediatric liver disease being triggered. These findings provide the basis for future translational studies on the interaction between genetic and environmental factors in the determination of the adult phenotype, which are of paramount importance for understanding and preventing the rise of obesity and associated non-communicable diseases in human populations with a thrifty genotype and leptin resistance.

\section{Declaration of interest}

The authors declare that there is no conflict of interest that could be perceived as prejudicing the impartiality of the research reported.

\section{Funding}

This work was supported by funds from the Spanish Ministry of Economy and Competitiveness (project AGL2010-21991-C03-03), co-funded by the Fondo Europeo de Desarrollo Regional (FEDER).

\section{Author contribution statement}

A G-B, S A, C O, C J L-B, R S-S, M L P-S, LT-R, M A and J G participated equally in conceiving and designing the study, acquiring data and conducting analyses, and drafting/editing the manuscript. All authors approve the content of this manuscript.

\section{Acknowledgements}

The authors thank the staffs of the INIA for skilled technical assistance. The essential support of P Cuesta and I Cano (Department of Research Support, Universidad Complutense de Madrid) for performing the statistical analyses is gratefully acknowledged. A G-B is a member of the EU Cooperation in Science and Technology (COST)-Action BM1308 'Sharing Advances on Large Animal Models (SALAAM)'.

\section{References}

Antipatis C, Grant G \& Ashworth CJ 2000 Moderate maternal vitamin A deficiency affects perinatal organ growth and development in rats. British Journal of Nutrition 84 125-132. (doi:10.1017/S0007114500001318)

Attie AD, Krauss RM, Gray-Keller MP, Brownlie A, Miyazaki M, Kastelein JJ, Lusis AJ, Stalenhoef AF, Stoehr JP, Hayden MR et al. 2002 Relationship between stearoyl-CoA desaturase activity and plasma triglycerides in human and mouse hypertriglyceridemia. Journal of Lipid Research $\mathbf{4 3}$ 1899-1907. (doi:10.1194/jlr.M200189-JLR200)

Barbero A, Astiz S, Lopez-Bote CJ, Perez-Solana ML, Ayuso M, Garcia-Real I \& Gonzalez-Bulnes A 2013 Maternal malnutrition and offspring sex determine juvenile obesity and metabolic disorders in a swine model of leptin resistance. PLOS ONE 8 e78424. (doi:10.1371/journal.pone. 0078424)

Bramlage KS, Bansal V, Xanthakos SA \& Kohli R 2013 Fatty liver disease in children - what should one do? Indian Journal of Pediatrics $\mathbf{8 0}$ S109-S114. (doi:10.1007/s12098-012-0826-5)

Caron-Jobin M, Mauvoisin D, Michaud A, Veilleux A, Noël S, Fortier MP, Julien P, Tchernof A \& Mounier C 2012 Stearic acid content of abdominal adipose tissues in obese women. Nutrition \& Diabetes 2 e23. (doi:10.1038/nutd.2011.19)

Charneca R, Nunes JLT \& Le Dividich J 2010 Body composition and blood parameters of newborn piglets from Alentejano and conventional

Published by Bioscientifica Ltd. 
(Large White $\times$ Landrace) genotype. Spanish Journal of Agricultural Research 8 317-325. (doi:10.5424/sjar/2010082-1192)

Christoffersen BO, Grand N, Golozoubova V, Svendsen O \& Raun K 2007 Gender-associated differences in metabolic syndrome-related parameters in Göttingen minipigs. Comparative Medicine 57 493-504.

Dabelea D \& Crume T 2011 Maternal environment and the transgenerational cycle of obesity and diabetes. Diabetes 60 1849-1855. (doi:10.2337/db11-0400)

Dawkins MJ 1966 Biochemical aspects of developing function in newborn mammalian liver. British Medical Bulletin 22 27-33.

Daxinger L \& Whitelaw E 2010 Transgenerational epigenetic inheritance: more questions than answers. Genome Research 20 1623-1628. (doi:10.1101/gr.106138.110)

D'Inca R, Gras-Le Guen C, Che L, Sangild PT \& Le Huërou-Luron I 2011 Intrauterine growth restriction delays feeding-induced gut adaptation in term newborn pigs. Neonatology 99 208-216. (doi:10.1159/ 000314919)

Douglas WR 1972 Of pigs and men and research: a review of applications and analogies of the pig, Sus scrofa, in human medical research. Space Life Sciences 3 226-234. (doi:10.1007/BF00928167)

Drake AJ \& Seckl JR 2011 Transmission of programming effects across generations. Pediatric Endocrinology Reviews 9 566-578.

Dunn GA, Morgan CP \& Bale TL 2011 Sex-specificity in transgenerational epigenetic programming. Hormones and Behavior 59 290-295. (doi:10.1016/j.yhbeh.2010.05.004)

Dyson MC, Alloosh M, Vuchetich JP, Mokelke EA \& Sturek M 2006 Components of metabolic syndrome and coronary artery disease in female Ossabaw swine fed excess atherogenic diet. Comparative Medicine $5635-45$.

Elder DA, Prigeon RL, Wadwa RP, Dolan LM \& D'Alessio DA $2006 \beta$-cell function, insulin sensitivity, and glucose tolerance in obese diabetic and nondiabetic adolescents and young adults. Journal of Clinical Endocrinology and Metabolism 91 185-191. (doi:10.1210/jc.2005-0853)

El-Kabbany ZA, Hamza RT, Ibrahim SA \& Mahmoud NH 2013 Dyslipidemia and hyperinsulinemia in children and adolescents with chronic liver disease: relation to disease severity. International Journal of Adolescent Medicine and Health 2 1-7. (doi:10.1515/ijamh-2013-0302)

El-Koofy NM, Anwar GM, El-Raziky MS, El-Hennawy AM, El-Mougy FM, El-Karaksy HM, Hassanin FM \& Helmy HM 2012 The association of metabolic syndrome, insulin resistance and non-alcoholic fatty liver disease in overweight/obese children. Saudi Journal of Gastroenterology 18 44-49. (doi:10.4103/1319-3767.91738)

Fernandez-Figares I, Lachica M, Nieto R, Rivera-Ferre MG \& Aguilera JF 2007 Serum profile of metabolites and hormones in obese (Iberian) and lean (Landrace) growing gilts fed balanced or lysine deficient diets. Livestock Production Science 110 73-81. (doi:10.1016/j.livsci.2006. 10.002)

Fishbein M, Mogren J, Mogren C, Cox S \& Jennings R 2005 Undetected hepatomegaly in obese children by primary care physicians: a pitfall in the diagnosis of pediatric nonalcoholic fatty liver disease. Clinical Pediatrics 44 135-141. (doi:10.1177/000992280504400205)

Fishbein MH, Mogren C, Gleason T \& Stevens WR 2006 Relationship of hepatic steatosis to adipose tissue distribution in pediatric nonalcoholic fatty liver disease. Journal of Pediatric Gastroenterology and Nutrition 42 83-88.

Foxcroft GR, Dixon WT, Novak S, Putman CT, Town SC \& Vinsky MD 2006 The biological basis for prenatal programming of postnatal performance in pigs. Journal of Animal Science 84 E105-E112.

Gallou-Kabani C \& Junien C 2005 Nutritional epigenomics of metabolic syndrome. Diabetes $\mathbf{5 4}$ 1899-1906. (doi:10.2337/ diabetes.54.7.1899)

Gluckman PD \& Hanson MA 2004 Living with the past: evolution, development, and patterns of disease. Science 305 1733-1736. (doi:10.1126/science.1095292)

Gonzalez-Bulnes A, Ovilo C, Lopez-Bote CJ, Astiz S, Ayuso M, Perez-Solana ML, Sanchez-Sanchez R \& Torres-Rovira L 2012
Gender-specific early postnatal catch-up growth after intrauterine growth retardation by food restriction in swine with obesity/leptin resistance. Reproduction 144 269-278. (doi:10.1530/REP-12-0105)

Hammon HM, Steinhoff-Wagner J, Schönhusen U, Metges CC \& Blum JW 2012 Energy metabolism in the newborn farm animal with emphasis on the calf: endocrine changes and responses to milk-born and systemic hormones. Domestic Animal Endocrinology 43 171-185. (doi:10.1016/j.domaniend.2012.02.005)

Haugen G, Hanson M, Kiserud T, Crozier S, Inskip H \& Godfrey KM 2005 Fetal liver-sparing cardiovascular adaptations linked to mothers slimness and diet. Circulation Research 96 12-14. (doi:10.1161/01.RES. 0000152391.45273.A2)

Houpt KA, Houpt TR \& Pond WG 1979 The pig as a model for the study of obesity and of control of food intake: a review. Yale Journal of Biology and Medicine 52 307-329.

Hulver MW, Berggren JR, Carper MJ, Miyazaki M, Ntambi JM, Hoffman EP, Thyfault JP, Stevens R, Dohm GL, Houmard JA et al. 2005 Elevated stearoyl-CoA desaturase-1 expression in skeletal muscle contributes to abnormal fatty acid partitioning in obese humans. Cell Metabolism 2 251-261. (doi:10.1016/j.cmet.2005.09.002)

Kleiner DE, Brunt EM, Van Natta M, Behling C, Contos MJ, Cummings OW, Ferrell LD, Liu YC, Torbenson MS, Unalp-Arida A et al. 2005 Design and validation of a histological scoring system for nonalcoholic fatty liver disease. Hepatology 41 1313-1321. (doi:10.1002/hep.20701)

Kong AP, Xu G, Brown N, So WY, Ma RC \& Chan JC 2013 Diabetes and its comorbidities-where East meets West. Nature Reviews. Endocrinology 9 537-547. (doi:10.1038/nrendo.2013.102)

Koyama K, Chen G, Lee Y \& Unger RH 1997 Tissue triglycerides, insulin resistance, and insulin production: implications for hyperinsulinemia of obesity. American Journal of Physiology 273 708-713.

Kwiterovich PO 2008 Primary and secondary disorders of lipid metabolism in pediatrics. Pediatric Endocrinology Reviews 5 727-738.

Lin G, Liu C, Feng C, Fan Z, Dai Z, Lai C, Li Z, Wu G \& Wang J 2012 Metabolomic analysis reveals differences in umbilical vein plasma metabolites between normal and growth-restricted fetal pigs during late gestation. Journal of Nutrition 142 990-998. (doi:10.3945/jn.111. 153411)

Marmer WN \& Maxwell RJ 1981 Dry column method for the quantitative extraction and simultaneous class separation of lipids from muscle tissue. Lipids 16 365-371. (doi:10.1007/BF02534964)

McPherson RL, Ji F, Wu G, Blanton JR Jr \& Kim SW 2004 Growth and compositional changes of fetal tissues in pigs. Journal of Animal Science 82 2534-2540.

Meng L, Luo N \& Mi J 2011 Impacts of types and degree of obesity on non-alcoholic fatty liver disease and related dyslipidemia in Chinese school-age children. Biomedical and Environmental Sciences 24 22-30. (doi:10.3967/0895-3988.2011.01.003)

Morales J, Pérez JF, Baucells MD, Mourot J \& Gasa J 2002 Comparative digestibility and lipogenic activity in Landrace and Iberian finishing pigs fed ad libitum corn- and corn-sorghum-acorn based diets. Livestock Production Science 77 195-205. (doi:10.1016/S0301-6226 (02)00063-5)

Muñoz G, Ovilo C, Silió L, Tomás A, Noguera JL \& Rodríguez MC 2009 Single- and joint-population analyses of two experimental pig crosses to confirm quantitative trait loci on Sus scrofa chromosome 6 and leptin receptor effects on fatness and growth traits. Journal of Animal Science $\mathbf{8 7}$ 459-468. (doi:10.2527/jas.2008-1127)

Nesto RW 2005 Beyond low-density lipoprotein: addressing the atherogenic lipid triad in type 2 diabetes mellitus and the metabolic syndrome. American Journal of Cardiovascular Drugs 5 379-387. (doi:10.2165/00129784-200505060-00005)

Ovilo C, Fernández A, Noguera JL, Barragán C, Letón R, Rodríguez C, Mercadé A, Alves E, Folch JM, Varona L et al. 2005 Fine mapping of porcine chromosome 6 QTL and LEPR effects on body composition in multiple generations of an Iberian by Landrace intercross. Genetical Research 85 57-67. (doi:10.1017/S0016672305007330) 
Ovilo C, Fernandez A, Fernandez AI, Folch JM, Varona L, Benitez R, Nunez Y, Rodrıguez C \& Silio L 2010 Hypothalamic expression of porcine leptin receptor (LEPR), neuropeptide Y (NPY), and cocaineand amphetamine-regulated transcript (CART) genes is influenced by LEPR genotype. Mammalian Genome 21 583-591. (doi:10.1007/ s00335-010-9307-1)

Ovilo C, Gonzalez-Bulnes A, Benítez R, Ayuso M, Barbero A, PérezSolana ML, Barragán C, Astiz S, Fernández A \& López-Bote C 2014 Prenatal programming in an obese swine model: sex-related effects of maternal energy restriction on morphology, metabolism and hypothalamic gene expression. British Journal of Nutrition 111 735-746. (doi:10.1017/S0007114513002948)

Paillard F, Catheline D, Duff FL, Bouriel M, Deugnier Y, Pouchard M, Daubert JC \& Legrand P 2008 Plasma palmitoleic acid, a product of stearoyl-coA desaturase activity, is an independent marker of triglyceridemia and abdominal adiposity. Nutrition, Metabolism, and CardiovascularDiseases 18 436-440. (doi:10.1016/j.numecd.2007.02.017)

Poudyal H \& Brown L 2011 Stearoyl-CoA desaturase: a vital checkpoint in the development and progression of obesity. Endocrine, Metabolic \& Immune Disorders Drug Targets 11 217-231. (doi:10.2174/ 187153011796429826)

Pruis MG, Lendvai A, Bloks VW, Zwier MV, Baller JF, de Bruin A, Groen AK \& Plösch T 2014 Maternal western diet primes non-alcoholic fatty liver disease in adult mouse offspring. Acta Physiologica 210 215-227. (doi:10.1111/apha.12197)

Ravelli GP, Stein ZA \& Susser MW 1976 Obesity in young men after famine exposure in utero and early infancy. New England Journal of Medicine 295 349-353. (doi:10.1056/NEJM197608122950701)

Rey AI, López-Bote CJ \& Sanz-Arias R 1997 Effect of extensive feeding on $\alpha$-tocopherol concentration and oxidative stability of muscle microsomes from Iberian pigs. Animal Science 65 515-520. (doi:10.1017/S1357729800008729)

Roberts EA 2005 Non-alcoholic fatty liver disease (NAFLD) in children. Frontiers in Bioscience 10 2306-2318. (doi:10.2741/1699)

Roseboom TJ, van der Meulen JH, Ravelli AC, Osmond C, Barker DJ \& Bleker OP 2001 Effects of prenatal exposure to the Dutch famine on adult disease in later life: an overview. Molecular and Cellular Endocrinology 185 93-98. (doi:10.1016/S0303-7207(01)00721-3)

Scheen AJ 2010 Central nervous system: a conductor orchestrating metabolic regulations harmed by both hyperglycaemia and hypoglycaemia. Diabetes \& Metabolism 36 31-38. (doi:10.1016/S12623636(10)70464-X)

Schwimmer JB, Behling C, Newbury R, Deutsch R, Nievergelt C, Schork NJ \& Lavine JE 2005 Histopathology of pediatric nonalcoholic fatty liver disease. Hepatology 42 641-649. (doi:10.1002/hep.20842)

Scully T 2012 Diabetes in numbers. Nature 485 S2-S3. (doi:10.1038/ 485S2a)

Shaw JE, Sicree RA \& Zimmet PZ 2010 Global estimates of the prevalence of diabetes for 2010 and 2030. Diabetes Research and Clinical Practice $\mathbf{8 7}$ 4-14. (doi:10.1016/j.diabres.2009.10.007)

Shelley HJ 1961 Glycogen reserves and their changes at birth and in anoxia. British Medical Bulletin 17 137-143.
Shingfield KJ, Bonnet M \& Scollan ND 2013 Recent developments in altering the fatty acid composition of ruminant-derived foods. Animal 7 132-162. (doi:10.1017/S1751731112001681)

Slyper AH 1998 Childhood obesity, adipose tissue distribution, and the pediatric practitioner. Pediatrics 102 e4. (doi:10.1542/peds.102.1.e4)

Spurlock ME \& Gabler NK 2008 The development of porcine models of obesity and the metabolic syndrome. Journal of Nutrition 138 397-402.

Suano de Souza FI, Silverio Amancio OM, Saccardo Sarni RO, Sacchi Pitta T, Fernandes AP, Affonso Fonseca FL, Hix S \& Ramalho RA 2008 Nonalcoholic fatty liver disease in overweight children and its relationship with retinol serum levels. International Journal of Vitamin and Nutrition Research 78 27-32. (doi:10.1024/0300-9831.78.1.27)

Sundaram SS, Zeitler P \& Nadeau K 2009 The metabolic syndrome and nonalcoholic fatty liver disease in children. Current Opinion in Pediatrics 21 529-535. (doi:10.1097/MOP.0b013e32832cb16f)

Temelkova-Kurktschiev T \& Hanefeld M 2004 The lipid triad in type 2 diabetes - prevalence and relevance of hypertriglyceridaemia/low high-density lipoprotein syndrome in type 2 diabetes. Experimental and Clinical Endocrinology \& Diabetes 112 75-79. (doi:10.1055/ s-2004-815753)

Torres-Rovira L, Astiz S, Caro A, Lopez-Bote C, Ovilo C, Pallares P, Perez-Solana ML, Sanchez-Sanchez R \& Gonzalez-Bulnes A 2012 Diet-induced swine model with obesity/leptin resistance for the study of metabolic syndrome and type 2 diabetes. Scientific World Journal 2012 Article no. 510149. (doi:10.1100/2012/510149)

Torres-Rovira L, Gonzalez-Anover P, Astiz S, Caro A, Lopez-Bote C, Ovilo C, Pallares P, Perez-Solana ML, Sanchez-Sanchez R \& Gonzalez-Bulnes A $2013 \mathrm{Effect}$ of an obesogenic diet during the juvenile period on growth pattern, fatness and metabolic, cardiovascular and reproductive features of swine with obesity/leptin resistance. Endocrine, Metabolic \& Immune Disorders Drug Targets 13 143-151. (doi:10.2174/ 1871530311313020002)

Trahair JT \& Sangild P 1997 Systemic and luminal influences on the perinatal development of the gut. Equine Veterinary Journal 24 40-50. (doi:10.1111/j.2042-3306.1997.tb05077.x)

Vobecky J, Vobecky JS, Shapcott D, Demers PP, Reid D, Fisch C, Blanchard R, Cloutier D \& Black R 1979 Food intake patterns of infants with high serum cholesterol level at six months. International Journal of Vitamin and Nutrition Research 49 189-198.

Ward SD, Melin JR, Lloyd FP, Norton JA Jr \& Christian JC 1980 Determinants of plasma cholesterol in children - a family study. American Journal of Clinical Nutrition 33 63-70.

Warensjö E, Ohrvall M \& Vessby B 2006 Fatty acid composition and estimated desaturase activities are associated with obesity and lifestyle variables in men and women. Nutrition, Metabolism, and Cardiovascular Diseases 16 128-136. (doi:10.1016/j.numecd.2005.06.001)

Witczak CA, Mokelke EA, Boullion R, Wenzel J, Keisler DH \& Sturek M 2005 Noninvasive measures of body fat percentage in male Yucatan swine. Comparative Medicine 55 445-451.

Yee JK, Phillips SA, Allamehzadeh K \& Herbst KL 2012 Subcutaneous adipose tissue fatty acid desaturation in adults with and without rare adipose disorders. Lipids in Health and Disease 11 19. (doi:10.1186/1476511X-11-19)

Received in final form 26 July 2014

Accepted 8 August 2014

Accepted Preprint published online 8 August 2014 http://joe.endocrinology-journals.org DOI: $10.1530 / J O E-14-0217$
() 2014 Society for Endocrinology Printed in Great Britain
Published by Bioscientifica Ltd. 